\title{
Entre vergonhas e silêncios, o corpo segredado. Práticas e representações que mulheres produzem na experiência da menstruação
}

\author{
Marlene de Fáveri* \\ Anamaria Marcon Venson*
}

\begin{abstract}
Resumo. Este artigo se insere na análise de práticas culturais e suas representações, vividas por mulheres de diferentes gerações, no sul do Estado de Santa Catarina, percebidas na experiência do ritual de passagem com o aparecimento da menarca. Procuramos compreender como as mulheres, na experiência da menstruação, constroem representações do feminino. A menstruação, como manifestação do corpo, é o que é na cultura, e, portanto, seus significados somente podem ser lidos no contexto de uma dada cultura. Para estas análises, a categoria gênero instiga para a compreensão de que os silêncios, norteados pelos sentidos de medo e vergonha, são construções culturais e trazem relações de poder, circunscritas na prescrição de papéis ditos do feminino, mostrando um corpo produzido por expectativas de gênero. Sob a perspectiva da história oral, foram preciosas as fontes da memória neste trabalho, interpretadas à luz das metodologias da História.

Palavras-chave: Menstruação. Relações de gênero. Representações. Corpo. Experiência.
\end{abstract}

Este ensaio analisa práticas culturais vividas por mulheres no sul catarinense, com relação ao corpo, à sexualidade, à manifestação da menarca e à experiência da menstruação, percebendo-as nas

\footnotetext{
* Professora do Departamento e Programa de Pós-Graduação em História da UDESC.

* Historiadora, mestranda em História pela Universidade Federal de Santa Catarina-UFSC.
} 
Entre vergonhas e silêncios, o corpo segredado...

redes de conversas entre vizinhas, amigas, mães, filhas, avós, como coisas do privado, acontecimento segredado, coisas de mulheres. A perspectiva de abordagem é a História Cultural, pois tratamos de diferentes formas de representação e práticas, e como são reelaboradas e reinventadas na cultura e nas relações, com aporte teórico nos estudos de gênero, experiência e memória. Dentre as variedades da História Cultural, Peter Burke observa, com pertinência, que os historiadores "têm de estudar a memória como uma fonte histórica, elaborar uma crítica da confiabilidade da reminiscência no teor da crítica tradicional de documentos históricos" (Burke, 2000, p. 72-73), instigando à escuta respeitosa dos depoimentos e às interpretações criteriosas para os estudos históricos.

As principais fontes desta pesquisa são as memórias de 14 mulheres, na faixa etária entre 33 e 89 anos de idade, moradoras das cidades das cidades de Turvo, Criciúma, Siderópolis, Meleiro e Forquilhinha, todas no sul do estado de Santa Catarina, colhidas no mês de julho de 2005. ${ }^{1}$ Os nomes são fictícios, e serão citados assim doravante a cada vez que elas falam, muito embora nenhuma tenha restringido o uso de suas memórias; assim as tratamos por uma questão ética e de respeito, e as entrevistas se encontram em anexo ao final deste texto. Convém pontuar que a maior parte das entrevistadas é do universo rural, ou nasceu e foi educada nesse universo, e tem educação escolar restrita; portanto, não estamos sugerindo que tais práticas e representações são universais.

Para interpretar as narrativas das mulheres, percebendo a produção discursiva que organiza a prática do segredo, é preciso ficar claro que esta é uma história do corpo, tanto dos silêncios sobre o corpo como dos discursos clandestinos e das transgressões. Michele Perrot, em Os Silêncios do corpo da mulher, atenta para o silêncio que envolve as mulheres. Apesar de o corpo feminino ser exposto no discurso dos poetas, dos médicos, dos políticos, as próprias mulheres não falam dele (Perrot, 2006). Solicitadas por nós e pouco dispostas a falar da sua experiência com a menstruação, essas mulheres se 
referem ao próprio corpo por metáforas: "o chico”, “o boi”, “tá com a boiada", "ficou mocinha", "assistida", "está assistindo", "tava naqueles dias", "regra", "bandeira vermelha", "o mês", "veio hoje", "eu vim", "vieni oggi", "sono cosi"” e tantas outras maneiras. Percebem-se estratégias de esconderijo, uma teia de significados e linguagem entendida por elas, códigos apreendidos e reproduzidos, falados em voz baixa.

Não pretendemos tentar universalizar o fato de que a menstruação é segredada ou ridicularizada, mas observar que em boa parte do mundo ocidental as pessoas utilizam códigos para falar do sangramento mensal das mulheres, bem como as nossas entrevistadas. Por exemplo, na língua inglesa, é coloquialmente usada a designação period (período), mas também a palavra curse (maldição). Também são usadas as expressões it is that time of the month (é aquele tempo do mês); I am on the rag, que significa "estou no pano", mas que poderia ser entendido com o mesmo sentido da expressão usada por nós "estou em maus lençóis"; I am riding the red tide (estou no período vermelho); I'm on the red flag (estou de bandeira vermelha); up on blocks, expressão usada para descrever a situação de um carro parado, talvez em conserto, sem as quatro rodas e sustentado por blocos ou tijolos, e é utilizada por mulheres e homens, em forma de gíria para menstruação. É como dizer que você está “fora de uso". Na língua alemã, são usadas as expressões ich binouf der roden welle (estou na onda vermelha), ich habe meine tage (estou tendo meus dias), ich habe die Regel (estou nas minhas regras), die monatliche sache (coisa mensal). As espanholas, quando menstruam, usam o mesmo termo dito em caso de doença: estoy mala. Para diferenciar as ocasiões, elas esclarecem: estoy mala, cosas de mijeres. E, então, segundo elas, todos entendem. $\mathrm{Na}$ Argentina, as mulheres dizem que estão indispuestas (indispostas), termo somente usado nessa situação. As italianas dizem que estão in quei giorni (naqueles dias), ou indisposta. Portanto, essa maneira segredada e codificada de falar da fisiologia feminina não advém necessariamente de desconhecimento, mas é prática cultural e está inclusa numa 
Entre vergonhas e silêncios, o corpo segredado...

lógica específica de pensar as mulheres. Não consideramos a menstruação um fato natural simplesmente, mas um fato social, marcado pela cultura e representações que essas mulheres constroem sobre seus corpos, e particularmente sobre a menstruação, inseridas num contexto social e cultural mais amplo.

$\mathrm{Na}$ cultura que estamos analisando, as transformações do corpo feminino na adolescência são marcadas por murmúrios de mãe para filha e que se perdem em seus pudores, e a primeira menstruação é uma surpresa vivida quase sempre no medo e na vergonha, como ouvimos de Cândida, 89 anos:

A gente era burra, a mãe não ensinava nada. Era tudo à cega. Era tudo escondido. Não sabia nada signor? Ah, ela explicou que quando vem a idade e a menstruação, que é a idade da gente. Assim a gente dizia: "vinha no mês". Tinha um pouco de vergonha, né, uma vez. Ninguém sabia nada, ninguém notava, era tudo escondido, as coisas. Eu acredito que nunca ninguém viu. Porque era tudo... como é que eu vou explicar... meio atrasado né... nunca ouvi nenhuma história sobre isso. Imagina, a gente ia lavar na sanga ${ }^{3}$ tudo escondido, porque ninguém via, a gente não mostrava pra ninguém.

Da mesma maneira que a menstruação, a menopausa ocorre numa semiclandestinidade. O prazer feminino é negado, e mesmo reprovado, pois se fala de frigidez feminina quase como se fosse um fato da natureza, e não como o resultado de práticas sociais. Mesmo nas conversas entre mulheres, durante as entrevistas, elas referiam-se à experiência da menstruação como algo que precisa ser silenciado, segredado. Perguntadas sobre a menarca, elas falavam de modo evasivo e desajeitado. Na perspectiva dessas mulheres, falar sobre menstruação é constrangedor, é vergonhoso. Elas usam uma linguagem codificada, falam entre pausas e silêncios, evidenciando que não mantêm a prática de falar sobre os assuntos do corpo, como fez Joana, 63 anos: 
Marlene de Fáveri e Anamaria Marcon Venson

A gente não dizia menstruação. A gente chamava... hum... deixa eu ver... sei lá! Era... não era menstruação... A gente dizia regra ou chico. É, não sei por quê, né. Depois de moça, a gente dizia “ó, tá com o chico". Pronto. Aí todo mundo já sabia.

O segredo e o silêncio envolvem o corpo dessas mulheres, e mais o pudor, constituem uma marca de sua feminilidade. As etapas da transformação do corpo feminino são vistas como uma mutação suave que encaminha as mulheres para a função de reprodutoras. São tecidas relações de segredo entre mãe e filha, e a ausência de educação sexual faz com que a primeira menstruação seja uma surpresa vivida, quase sempre, no medo e na vergonha.

Numa pesquisa feita em Navegantes (SC), em 1988, intitulada Fontes Educativas que as Mulheres Camponesas de Navegantes têm sobre a Sexualidade - proposta educativa, em que foram entrevistadas dezesseis mulheres, Marlene de Fáveri observou que as informações sobre a sexualidade circulam entre as mulheres - tias, amigas, vizinhas, irmãs, comadres etc. - em conversas transpassadas de vergonha de falar do próprio corpo. Seus conhecimentos consistem em expe-riências pessoais, em observações empíricas, posto que não receberam nenhum tipo de educação sexual formal (Fáveri, 1989). Desse modo, também Cecillia, 61 anos, rememora como tomou conhecimento do "aparecimento do sangue":

Eu nunca esqueço que eu descobri que a mulher menstruava... Ninguém me falou. E eu fui na paróquia e ali tinha livro. E eu peguei um livro e estava escrito ali. Que estava escrito que a menina quando tinha 12 ou 13 anos... enfim... ela... menstruava [...] Não estava escrita essa palavra. Aquela vez não se dizia menstruação, né. Dizia que aparecia o sangue, entendeu?! Eu não sei explicar assim direitinho se foi assim que estava escrito. Mas eu sei que não era "menstruação". Isso apareceu depois. Aí eu menstruei. Ali que fechou o que eu tinha lido. Dali que eu descobri. Senão, eu menstruava e não sabia o que era...

Anos 90, Porto Alegre, v. 14 n. 25, p.65-97, jul. 2007 
Entre vergonhas e silêncios, o corpo segredado...

Algumas mulheres, em especial aquelas com mais de 55 anos na data da entrevista, relataram que nada ou quase nada sabiam na data da menarca. Tampouco foram propriamente ensinadas por mães, irmãs ou amigas sobre o acontecimento. Cecília recorreu a um livro da Igreja; outras mulheres viveram um silêncio solitário, e aprenderam, na experiência da menstruação, que ser mulher é ser discreta, é ser calada, é aceitar o seu corpo com resignação e sem indagações, afinal, mistério é um atributo do feminino. As mulheres sussurram, têm segredos. Falam entre elas, têm um lugar específico: em casa, escondidas, resguardadas, protegidas. Determinou-se para a mulher o espaço privado, e isso é visto, muitas vezes, como inevitável jogo da natureza, ao invés de ser compreendido como construção cultural: a mulher teria certas debilidades em função de seu sexo, seria desprovida da disposição masculina. E entre si, resguardadas no espaço privado, entre cochichos e reticências, elas elaboram sua sociabilidade. Augusta, 78 anos, relembra assim:

Eu descobri porque lá em casa da minha mãe, eu me escondia atrás das portas pra escutar, pra ver o que elas falavam, as mulheres. Aí elas contavam. Eu me tocava que alguma coisa de diferente tinha que ser. E daí a gente, então, ouvia elas falarem, e dava pra entender que alguma coisa tinha. Mais ou menos alguma coisa tinha de diferente. Eu chegava a prender os meus irmãos pra ficar atrás da porta escutando.

Escutar atrás das portas... Curioso jeito de informar-se! E, dessa maneira, várias outras disseram conversar com as amigas da escola, desviando-se das normas de calar, mas sempre reproduzindo medo e vergonha. Muitas mulheres não receberam educação sexual formal, mas a reprodução de práticas também se dá, certamente, por imitação de gestos e apropriação de condutas. Cada uma tem uma experiência singular em seus corpos sexuados que as fazem mulheres, num contexto de revolta ou de assujeitamento. Para Michel Foucault, o discurso tem materialidade, produz efeitos. Essas mulheres das 
quais estou falando aprenderam a ser mulheres vivendo e produzindo os seus corpos transpassados por pudores excessivos, experimentando um cotidiano de segredo e vergonha e, por vezes, transgredindo, também em segredo. Na fala de algumas mulheres, a experiência da menstruação é um rito que dá início ao processo de construir-se como mulher. Maria, 57 anos, relembra como se percebeu diferente em relação aos colegas de escola quando "ficou moça":

E naquele dia eu fui pra escola. Aí na hora do recreio, todo

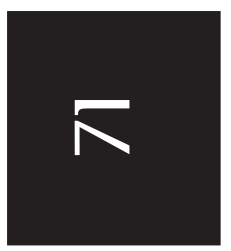
mundo ia brincar e correr igual a loucos no pátio né. E eu fiquei sentada, bem quietinha, porque eu me sentia diferente... Eu já estava com aquele trombolho no meio das pernas. Se eu corresse, de repente aquilo vai cair, né?! Aí eu fiquei quieta né...

Lembramos, aqui, da famosa acepção de Simone de Beauvoir: "não se nasce mulher, torna-se mulher", comumente usada em trabalhos que discutem gênero. Para essas mulheres, sangrar significou uma nova leitura de seus corpos e a construção de um novo senso de si: elas assumem um novo papel, um novo estilo de vivenciar o corpo, adquirem uma nova postura de maneira propositada. Elas não se identificam mais com as outras crianças que brincam sem medo; elas sentem-se diferentes, agora como mulheres, e, por isso precisam se cuidar e esconder o corpo. Sob uma análise de gênero, podemos perceber como os indivíduos se organizaram em sociedade identificando-se como mulheres ou homens, e como definiram para si um modo de viver o corpo.

Joan Scott, em Gênero: uma categoria útil de análise histórica, define gênero com a conexão de duas proposições principais: "O gênero é um elemento constitutivo de relações sociais fundadas sobre diferenças percebidas entre os sexos, e o gênero é um primeiro modo de dar significado às relações de poder" (Scott, 1990, p. 14). Para ela, as relações de gênero se constituem com elementos simbólicos culturalmente disponíveis, que são articulados de maneira binária 
Entre vergonhas e silêncios, o corpo segredado...

para representar o feminino e o masculino como conceitos fixos e atemporais. E, ainda, que o poder masculino não está só nas relações entre os sexos, mas se estende por toda a sociedade. Portanto, podemos utilizar a categoria gênero não só para analisar as relações entre homens e mulheres, mas também para compreender a dinâmica social e política.

A noção de Scott de que gênero é o que constitui as "relações sociais fundadas sobre diferenças percebidas entre os sexos" pode sugerir que há um corpo a priori que é percebido e que significa as relações de poder. Entendemos - apropriando-nos de Laqueur (2001), Fausto-Sterling (2001), Nicholson (2000) - que tudo que se produz sobre o corpo e o sexo já contém em si uma reivindicação sobre gênero; então, pensamos o "corpo" como um sistema que produz e reproduz significados e é produzido por eles em ações simultâneas e combinadas. Não há um corpo a priori, mas corpos construídos por discursos, corpos que existem na experiência. Os corpos são o que são na cultura, e não há um corpo "natural”, mas um corpo produzido por expectativas de gênero.

O que se diz sobre os corpos, as verdades sobre os corpos e a sexualidade humana são um componente das lutas morais, sociais e políticas travadas em nossas culturas. A verdade é sempre construída nos diálogos, nas relações de saber e poder. Fausto-Sterling, bióloga e feminista, argumenta sobre a maneira como nossos corpos incorporam e confirmam as verdades sobre a sexualidade e como essas verdades dão forma ao nosso ambiente cultural (Fausto-Sterling, 2001). A representação das mulheres como seres descontrolados, fragilizados, dominados pelas emoções, foi elaborada por discursos construídos para justificar a idéia de que às mulheres cabe o âmbito privado, o interior, a proteção do lar. Essa idéia não é eterna, ela tem uma história. FaustoSterling coloca que as normas de gênero têm motor social, e não científico, e alerta para o invisível poder político da ciência:

Nossos corpos são complexos demais para dar respostas claras sobre a diferença sexual. Quanto mais procuramos uma base

Anos 90, Porto Alegre, v. 14, n. 25, p. 65-97, jul. 2007 
Marlene de Fáveri e Anamaria Marcon Venson

física simples para o "sexo", mais claro fica que o sexo não é uma categoria física pura. Aqueles sinais e funções corporais que defi-nimos como masculino ou feminino já vêm misturados em nossas idéias sobre o gênero. (FAUSTO-STERLING, 2001:19).

A modernidade ocidental (as entrevistadas herdaram muito desse contexto) consolidou, no plano ideológico, o pensamento dicotômico em torno de categorias como público/privado, razão/ emoção, que são categorias associadas ao par masculino/feminino. Nota-se que esses pares opostos foram organizados de maneira hierarquizada, de modo que as categorias privado, emoção e feminino estão em lugar de inferioridade se relacionadas aos seus pares público, razão e masculino. Assim, entendemos o mundo a partir de dicotomias.

Para Linda Nicholson, nossas propostas sobre as "mulheres" surgem de nossos lugares na história e na cultura, são atos políticos que refletem os contextos nos quais estamos e os futuros que gostaríamos de ver. A partir disso, ela historiciza e desconstrói as categorias "gênero" e "mulher". A articulação entre sexo, como dado na natureza, e gênero, como investimento cultural sobre os corpos sexuados, constitui o que ela chama de fundacionalismo biológico, concepção que não compreende a noção de que mesmo as idéias sobre o corpo e o sexo variam nas sociedades. E, ainda, tal noção reconhece as diferenças entre mulheres de forma limitada, pois prevê que o que há de comum entre elas se deve ao sexo, e que este gera o que há de comum em termos de gênero, e indica que o que há de diferente se deve a categorias como classe e raça. (Nicholson, 2000). Portanto, para analisar a experiência da menstruação, é necessário destituir-se da noção de que o sangramento mensal marca naturalmente as mulheres para a debilidade, a fragilidade e o sofrimento. Há diferentes formas de vivenciar essa experiência, diferentes maneiras de conceber e significar os corpos.

Thomas Laqueur, em Inventando o sexo, aponta como, partir dos séculos XVII e XVIII, o corpo foi usado para explicar a distinção de

Anos 90, Porto Alegre, v. 14 n. 25, p.65-97, jul. 2007 
Entre vergonhas e silêncios, o corpo segredado...

mulheres e homens, justamente na época em que mudanças sociais organizaram uma separação maior entre as esferas pública e privada. Dentro dessa perspectiva, a natureza sexual da mulher foi modificada, redefinida, debatida, de maneira que a mulher, antes significada como ser apaixonado e de sexualidade insaciável, foi substituída pela mulher frígida, cuja ansiedade é canalizada para a reprodução (Laqueur, 2001). Essa noção foi muito conveniente para justificar a idéia de que à mulher cabe o âmbito privado, a segurança do lar. Mary Jane Paris Spink, em $A$ cidadania em construção, analisa a tensão entre a inclusão potencial e a exclusão efetiva da mulher da vida pública no processo de legitimação da ordem burguesa, e percebe que esta foi resolvida pela divisão dos espaços sociais: as diferenças biológicas correspondem às diferenças nas esferas de atuação - a esfera privada para a mulher, a pública para o homem (Spink, 1994).

Vemos que as nossas idéias sobre gênero, sobre sexo, sobre a fisiologia feminina e a menstruação são resultado de disputas travadas na nossa cultura, que constituem relações de poder. Os vários discursos médicos, religiosos, jurídicos, filosóficos encontram-se e debatemse, são reelaborados e reapropriados na cultura. Assim, também as nossas entrevistadas se apropriam desses discursos e elaboram suas próprias representações particulares, bem como muitos desses discursos autorizados se constroem a partir da racionalização e reelaboração de parte do conhecimento popular e comum.

Portanto, os corpos são o que são na cultura, ressignificam-se, reelaboram-se. Guacira Lopes Louro, em Corpos que escapam, aponta como os sujeitos são examinados, classificados, ordenados, nomeados e definidos pelas marcas que são atribuídas a seus corpos. Cada grupo, e cada cultura, elege formas legítimas de interpretar as marcas e as características dos corpos para definir os sujeitos. Marcas de raça, de gênero, de etnia, de classe ou de nacionalidade, marcas que decidem o lugar social de cada um (Louro, 2005).

Neste trabalho, procuramos compreender como as mulheres, na experiência da menstruação, constroem representações do fe- 
minino. A menstruação, como manifestação do corpo, é o que é na cultura; portanto, seus significados somente podem ser lidos no contexto de uma dada cultura: a linguagem, os signos, as convenções, os códigos, os adornos, os cheiros, os comportamentos, os gestos - são todos dispositivos culturais. Louro enfatiza que não há como isolar natureza e cultura:

Os significados dos corpos deslizam e escapam, eles são múltiplos e mutantes. Até mesmo o gênero e a sexualidade - aparentemente deduzidos de uma "base" natural - são atributos que se inscrevem e se expressam nos corpos através das artimanhas e dos artifícios da cultura. Gênero e sexualidade não são definições seguras e estáveis, mas históricas e cambiantes. Deve-se reconhecer que a maioria das sociedades possui algum tipo de distinção masculino/feminino, e que essa distinção geralmente é relacionada ao corpo. Contudo, isso não quer dizer que os corpos são "lidos" ou compreendidos do mesmo modo em qualquer tempo ou lugar, nem que seja atribuído valor ou importância semelhante às características corporais em distintas culturas. (Louro, 2005, parágrafo 9).

Mesmo sem saber do que se tratava aquele sangue, de onde vinha ou qual era a sua função, as mulheres das quais estamos falando aprenderam que aquela era uma marca da feminilidade e que precisavam escondê-la. Elas disseram que aprenderam a "defender-se", "safarse", "aprecatar-se", "precaver-se" daquele sangue com pedaços de pano, que podiam ser lençóis velhos ou pelúcias especiais. Algumas costuravam o tecido na própria calcinha, outras usavam toalhinhas higiênicas. Outras lembraram das mães e das sogras, que não usavam calcinha e precisavam amarrar as anáguas entre as pernas para absorver o sangue. Elas próprias costuravam seus panos, que chamavam forrinhos, e os escondiam dos olhos dos outros, principalmente dos olhos dos homens.

Augusta, 78 anos, lembra que, quando não tinha tempo de ir até a sanga, escondia os forrinhos "sujos" debaixo do colchão. Algumas

Anos 90, Porto Alegre, v. 14 n. 25, p.65-97, jul. 2007 
Entre vergonhas e silêncios, o corpo segredado...

estendiam os forrinhos lavados de maneira que ficassem disfarçados entre as outras roupas, e outras disseram que, muitas vezes, o segredo era suficiente para que os irmãos nem percebessem, ou não "atinassem" o que eram aqueles panos. E essa prática de esconder o corpo, esconder as marcas do corpo feminino, produz subjetividade.

Foucault, em História da Sexualidade, vê na modernidade um incentivo e proliferação de práticas sexuadas, sem, entretanto, abandonar a hegemonia da sexualidade binária e do eixo reprodutivo (Foucault, 1988). As memórias das nossas entrevistadas deixam entrever que elas aprenderam a controlar, segredar, economizar as palavras para falar da sexualidade. Elas se preparam para ser mulheres-mães. Não estão proibidas de exercer a sexualidade; no entanto, sua sexualidade é controlada e definida: sexualidade para maternidade. Discursos contínuos e ininterruptos, afinal, uma mulher não se faz no dia em que menstrua, mas sim reiteradamente por toda a vida, constituem esses sujeitos-mulheres destinadas à contenção, à discrição, como relembra Verônica, 33 anos: "Às vezes alguma amiga comentava com a mãe, e a mãe disfarçava e avermelhava e saía e não queria saber do assunto. Era igual a fugir da morte né...”.

Percebemos nas memórias das nossas entrevistadas que elas foram educadas para serem mães, de modo que as preocupações em torno do seu corpo e do seu sexo são preocupações com a maternidade. Salete, 56 anos, contou-nos: "A minha filha é uma calamidade pública. [...] Gente, uma vez que ela trabalhava, Santo Deus, era um escândalo que fazia. Dava nela umas crises muito feias... Até eu vou falar uma coisa. Me deu até um medo que ela nunca ia poder ter filho!".

Esses depoimentos mostram que se a menstruação era um acontecimento da ordem do proibido, do escândalo, e a ausência dela era considerada doença, principalmente porque enunciava a possibilidade de não poder exercer a maternidade, coisa que poderia constituir um problema para um futuro casamento. No entanto, é interessante notar que o "menstruar" já é relacionado a um estado 
doentio, fato que se insere em certa lógica de pensar os corpos femininos como imperfeitos. Para essas mães, este é o caminho desejado para as filhas: casar, engravidar. Entre outras coisas, consideradas não tão importantes, o casamento foi destino para aquelas mulheres.

Joan Scott, no artigo Experiência, operacionaliza o conceito e procura redefinir o seu significado para o estudo da história. Para ela, a experiência já é uma interpretação e precisa de interpretação. O que se conta como experiência não é nem auto-evidente, nem definido, mas sempre contestável e político. Então, o estudo da experiência:

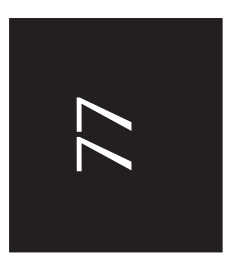

[...] deve questionar sua posição enquanto origem da narrativa histórica. Isso vai acontecer quando os/as historiadores/as tiverem como projeto não a reprodução e a transmissão de um conhecimento ao qual se chegou pela experiência, mas sim a análise da produção desse conhecimento. [...] Experiência é, nessa abordagem, não a origem de nossa explicação, mas aquilo que queremos explicar. (Scott, 1999, p. 48).

Para Scott, as noções de identidade e experiência não deveriam ser vistas como categorias auto-evidentes. Não há como recuperar a realidade dos objetos vistos, mas os/as historiadores/as devem tentar compreender os processos discursivos, que são complexos e mutáveis, pelos quais as identidades são atribuídas, os processos discursivos que são ignorados e que conseguem seus efeitos porque não são percebidos. Percebemos, nas falas dessas mulheres que entrevistamos, que elas experimentaram a prática do segredo, do medo, da vergonha, e essa experiência particular de temer o corpo marca suas memórias e as constitui como mulheres.

Scott atenta para a importância da questão da representação na análise da memória. Categorias sociais, compreensão pessoal e linguagem estão inter-relacionadas e não são reflexos diretos umas das outras. E pergunta: "existe um domínio da identidade pessoal fora das restrições sociais?”. Sua resposta é que o pessoal e o social estão imbricados um no outro, e que os dois são historicamente 
Entre vergonhas e silêncios, o corpo segredado...

variáveis. "Os significados das categorias da identidade mudam, e, com elas, as possibilidades de pensar o 'self”" (Scott, 1999, p. 48).

Portanto, a partir de Scott, compreendemos que, ao analisar a memória da experiência, não há como encontrar uma narrativa sobre a sociedade, o público, o político; e outra, sobre o indivíduo, o privado, o psicológico; porque a experiência se dá no imbricamento de todos esses âmbitos. Essas mulheres cujas memórias estamos analisando compartilham representações culturais acerca da menstruação, como, por exemplo, a idéia de que precisam escondê-la; mas cada uma delas, à sua maneira, reelabora sua própria representação. E o silêncio reproduzido por elas insere-se na lógica social de controle da sexualidade.

Se a experiência está na cultura, percebida nas teias do cotidiano, é sempre relacional. A categoria gênero auxilia sobremaneira nas análises dos dados, haja vista que a menstruação é uma característica sexual que tem justificado diferenças de gênero. As meninas aprendem na experiência da menstruação que mostrar ou mencionar os assuntos do corpo é vergonhoso, aprendem a incorporar a vergonha, e o sentido da menstruação é apreendido e reelaborado para marcar o feminino no silêncio e sombra, como vemos na fala de Verônica, 33 anos:

Graças a Deus, nunca passou. Mas em casa assim quando vinha bastante aí vazou na cama. Simplesmente levantei, tomei banho e continuei [...] Ah, sim, fui lavar escondida. Não, nem contei pra mãe. Isso ali foi meio no começinho acho [...] A vergonha. A gente foi criada assim, com vergonha...

O relato da experiência não seria história se não fosse ouvido dentro de uma produção discursiva. O relato em si não daria conta dos significados e sentidos produzidos. E a menarca é significada como a primeira experiência de ser mulher, e é mesmo uma marca que condiciona a feminilidade; afinal, na nossa cultura, a infância e o período da menopausa são dessexualizados porque não têm

Anos 90, Porto Alegre, v. 14, n. 25, p. 65-97, jul. 2007 
função reprodutiva, e na cultura de nossas depoentes, a maternidade é o destino esperado para essas mulheres.

É no olhar do outro que nos fazemos diferentes, que demarcamos os sentidos. Portanto, a experiência da menstruação produz subjetividades de gênero na medida em que marca diferenciações: à mulher cabe o silêncio, a vergonha, o segredo, o privado. E, aqui, estabelece-se uma relação de poder, posto que as meninas/mulheres se diferenciam dos meninos/homens na medida em que elas aprendem que devem temer o olhar deles, esconder, recear.

Nas memórias, nos depoimentos, notamos os sentidos e as marcas de como lidaram com as roupas, o cuidado de "tampar" o corpo, não tornar visível o fato de estar menstruada, e imaginamos as sensações de medo, de insegurança, de vergonha, os suores que essas preocupações causaram nessas mulheres. Quantas coisas deixaram de fazer, a quantos lugares deixaram de ir, quantos prazeres deixaram de sentir porque estavam tão envergonhadas de si. Essa maneira de construir papéis pode ser uma maneira de estabelecer relações de poder: às moças cabe a vergonha do corpo, o medo do olhar dos homens, o medo de engravidar. Esse pudor excessivo poderia servir para assegurar a ordem familiar, para evitar gravidezes inconvenientes, para resguardar a honra. Então, a experiência individual da menstruação vivida no medo e na vergonha está inclusa em certo modo de organização social e familiar. Cecília, 61 anos, rememora, com um pouco de mágoa na voz, que sua mãe não falava dos assuntos do corpo porque achava aquilo um pecado. Notamos, nas entrevistas, que o pecado permeia a vergonha. A representação do corpo como pecado assegura o controle da sexualidade, e as normas de segredar, de recear, de temer tornam-se práticas e são vividas por essas mulheres. Essa construção do corpo como lugar de pecados vem de longa data, através de discursos religiosos muitas vezes reproduzidos pelas nossas entrevistadas. Em conversas informais, ouvimos que as mulheres grávidas "de antigamente" não saíam de casa nem mesmo para ir à Igreja, pois tinham vergonha de seu estado: a barriga

Anos 90, Porto Alegre, v. 14 n. 25, p.65-97, jul. 2007 
Entre vergonhas e silêncios, o corpo segredado...

era uma declaração de que tinham tido relações sexuais. A menstruação também é uma marca do sexo das mulheres e, portanto, é motivo de vergonha. Afinal, conforme os discursos religiosos, o sexo é em si um pecado, e é tolerado somente para função reprodutiva. Esses discursos construíram normas de condutas, definiram papéis que, mesmo reapropriados e reapresentados, foram (e ainda são) vividos e praticados.

A Igreja construiu e manteve por séculos a idéia de que o corpo é impuro, sujo, lugar de pecado. Em Eunucos pelo Reino de Deus: mulheres, sexualidade e a Igreja Católica, Uta Ranke-Heinemann faz uma investigação de como a Igreja Romano-Católica tratou a sexualidade, a contracepção, o prazer e as mulheres. A autora analisa a proibição do coito com a mulher menstruada pelo cristianismo, especialmente na Antigüidade, justificada pelas crenças de que o sangue menstrual debilitaria a vitalidade do sêmen ou de que as crianças concebidas durante o período menstrual nasceriam deficientes. Próximo da modernidade, dados os avanços da medicina, essas idéias foram pouco a pouco abandonadas. No entanto, o coito durante a menstruação era considerado "pecado venial", impróprio, que demonstrava falta de autocontrole. Essa relação só seria justificada para superar forte tentação carnal ou para atenuar brigas conjugais (Ranke-Heinemann, 1996, p. 32-38).

Berriot-Salvadore, em $\mathrm{O}$ discurso da medicina e da ciência, investiga representações/práticas do corpo feminino e aponta que, desde a Antigüidade, o sangue menstrual foi investido de poder maléfico, de poder de envenenar, estragar (Berriot-Salvadore, 1991), como também percebeu Ranke-Reinemann sobre a construção da periculosidade do sangue menstrual pela Igreja. E Agnès Fine, em Leite envenenado, sangue perturbado, analisa depoimentos de mulheres francesas nos anos 1970 e encontra as mesmas representações reinventadas e reelaboradas, mas presentes e praticadas (Fine, 2003).

Nas memórias das nossas entrevistadas, esses mitos que demonizam a menstruação e culpabilizam as mulheres perduram de 
várias formas nos hábitos, nos medos e nas práticas sociais ainda hoje, reapresentados mas praticados. Salete, 56 anos, contou-nos que:

Menstruada não ia carpir [capinar] feijão, porque senão o feijão ia morrer. E lá no porco, se a guria dizia: "Eu estou menstruada", então tu fica aqui. Não vai nem lá perto. E as outras que não estavam iam né! Porque diz que estragava a carne por causa da temperatura não sei do quê. [...] E eu sei também que tinha certa gente que tinha as crenças, mas não eram de origem italiana [Salete é de "origem" italiana], era

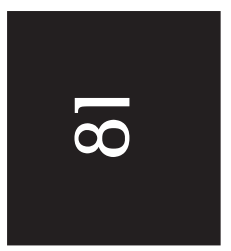
gente brasileira, eram os agregados, eles achavam que se a mulher tivesse grávida e passasse numa roça de feijão, o feijão morria. Grávida não, menstruada. É, a roça secava. Amarelava tudo e secava.

A experiência está na cultura, ou seja, as pessoas só podem relatar se viveram, porque estavam inseridas num grupo social que produzia e reproduzia representações que eram e são ainda apropriadas e vivenciadas. Roger Chartier nos auxilia na percepção das representações herdadas, que são culturais, sobre o corpo e suas manifestações. Segundo esse historiador, não há separação entre real e representação. O real é tal qual é representado, e representar é o modo como nós apreendemos, como nós decodificamos o real. A representação é a maneira individual de ver o mundo, que é perpassada pela condição de existência: classe, gênero, raça/etnia, cultura, idade, escolaridade, etc. Chartier discute a maneira como uma cultura construiu seus modos de significar, de atribuir sentidos, ou seja, a maneira como o real aparece no tempo e no espaço (Chartier, 1994). Um dos temas que foi recorrente nas falas de todas as nossas depoentes é a menstruação representada/associada à sujeira, ou sujo/a, nojo, nojeira.

Georges Vigarello, em O Limpo e o Sujo, faz uma história do polimento do comportamento e de um crescimento do espaço privado e do auto-regramento, dos cuidados do indivíduo para consigo mesmo. Ele procura sensibilidades perdidas e investiga diversos 
Entre vergonhas e silêncios, o corpo segredado...

modos de sentir e explicar a noção de limpeza através da história da França. O autor insiste na idéia de que a noção de "limpeza" é construída; e, ainda, é construída, necessariamente, relacionada às idéias acerca do corpo. Segundo Vigarello, existe um imaginário do corpo e as normas precisam interagir com ele:

O corpo nunca é "passivamente" habitado por elas [normas]. É preciso até que se modifiquem as imagens do corpo para que as regras possam se alterar. É preciso que se transformem as representações latentes do corpo, por exemplo, as que ditam seus funcionamentos e suas eficácias. Nesse caso, uma história da limpeza corporal implica uma história mais ampla e mais complexa. É que todas essas representações, dando ao corpo seus limites, desenhando suas aparências ou sugerindo seus mecanismos internos, têm antes de tudo um terreno social. (Vigarello, 1996, p. 03-04).

Portanto, a noção do que é sujo ou limpo é produzida na cultura, e está inserida na lógica particular de cada sociedade em compreender o mundo. As memórias das nossas entrevistadas reproduzem representações da menstruação coladas à noção de sujeira, e isso remete a uma lógica ampla de entender o corpo como sujo. Para justificar esse sentido atribuído ao mênstruo, elas, as depoentes, argumentam que sentem um odor desagradável. Vigarello alerta para o fato de que a relevância dada aos odores é cultural. Percebemos que o tal odor do sangue menstrual produz sentimentos de aversão nessas mulheres e é, simultaneamente, produzido por certa representação cultural de que o corpo feminino é sujo.

A idéia de que o sangue menstrual tem odor desagradável é pertinente à nossa lógica de pensar os corpos e, especialmente os corpos de mulheres, como inferiores, imperfeitos. As mulheres elaboram e reproduzem representações de seus corpos, mas essas representações são possíveis dentro de certo contexto, e elas provêm de uma certa perspectiva de inferiorização dos signos de feminilidade. 
Por muito tempo, o corpo feminino foi compreendido como deficiente em racionalidade, algo intermediário entre o corpo do homem e o corpo animal, e essa idéia aparece reelaborada no discurso de Salete, 56 anos, que fala com espontaneidade da "baixeza" do seu corpo:

É o mesmo sangue de um bicho depois que ele sai ele fica ali, aquele mau cheiro, um mau cheiro, é a coisa que primeiro fica é o mau cheiro. Saiu de manhã pra até à tarde, até à noite. A gente usava aquele paninho, mas ficava um tempo com o pano, um meio dia, um dia, como que vai ter no final do dia aquele sangue que saiu ali?! Olha, sem mentira nenhuma, é cheiro de podre mesmo.

No entanto, Augusta, 78 anos, faz uma leitura diferente: "Não, eu pra mim nunca notei o cheiro. Vai ver alguém facilitou e deixou passar do ponto. Porque não tinha chuveiro né... a pessoa se lavava, mas não dava pra lavar tudo bem direitinho".

Augusta e Salete justificam o tal odor dizendo que este se dava por higiene mal feita. Elas usavam os forrinhos, que não eram muitos práticos, e, por certo, hoje têm uma noção de higiene diferente devido às novidades no mercado - uma infinidade de acessórios para lidar com a menstruação e seus efeitos. No entanto, a idéia de que o corpo é sujo em si permanece nos depoimentos de forma contraditória. Vejamos o que diz Alice, 54 anos:

A minha filha uma vez reclamou: "bah, mas a mãe tá com um cheiro, um cheiro!". E eu tava mesmo. Eu tinha uma menstruação muito catinguenta. Eu mesma sentia. Quando tu vai trocar a roupa, ou tomar banho, quando tu vai no banheiro pra... pra usar o banheiro, tu sente aquele cheiro que sai de ti, aquela coisa fedorenta. Eu sentia. A minha menstruação era catinguenta. Não sei. É um cheiro de podre.

Norbert Elias, em O Processo Civilizador, investigou como a sociedade de corte vai lentamente "educando" as mulheres e os 
Entre vergonhas e silêncios, o corpo segredado...

homens para a polidez, os sentimentos de vergonha e repugnância das fezes e urina, num esforço para o autocontrole das pulsões (Elias, 1994). Aqui, essas mulheres são educadas no processo de civilidade para esconder a menstruação, camuflar os odores do seu sexo de modo que elas aprendem a envergonhar-se dele.

Luisa, 60 anos, também diz que o cheiro desagradável aparece quando mantém o mesmo absorvente higiênico por muito tempo. Mesmo assim, reproduz, como todas as outras depoentes, a representação de sujeira/nojo do sangue menstrual:

Eu acho que o cheiro que tem é característico da própria menstruação né... Não tem... O cheiro que acho... Não acho que seja cheiro ruim. Eu já ouvi também gente dizer que tem cheiro ruim e que incomoda. Mas isso nunca me preocupou, eu nunca achei nojento a ponto de achar que os outros estavam perto de mim e estavam sentindo o cheiro.

As etapas da fisiologia feminina são investidas de elaborações culturais. Tanto mistério em torno dos corpos das mulheres serve para justificar a necessidade de regulá-los constante-mente ao controle social: a magia, a religião e, contemporaneamente, a medicina produzem discursos sobre a "complicada" fisiologia feminina. Idéias que aproximam as mulheres da natureza e que produzem o homem como o ser completamente humano. Tais elaborações são feitas de modo que o corpo de homem seja representado com uma certa racionalidade, com uma certa lógica, enquanto o corpo de mulher é produzido como descontrolado, complexo, carregado do mistério que cabe à natureza.

Essas representações se evidenciam, por exemplo, no dizer de Salete, 56 anos:

[...] a gente não deixava de fazer nada porque estava menstruada, mas aí varia de família. Eu sei que tinha família que não podia fazer nada quando estava menstruada. $\mathrm{O}$ dia pra

Anos 90, Porto Alegre, v. 14, n. 25, p. 65-97, jul. 2007 
Marlene de Fáveri e Anamaria Marcon Venson

gente era igual. A gente continuava a mesma coisa. Se dizia que não era doença. É algo natural, né. A gente não tinha aquilo como doença. A gente foi educada assim. Tinha que continuar a vida a mesma coisa. A gente ia cortar banana, tu vê! A mesma coisa. E ainda, por incrível que pareça, o corte de banana era cada 25 a 30 dias. Então, pegou uma rotina que eu estava... que fiquei anos [ estalou os dedos] ou grávida ou menstruada quando eu ia pra ir cortar banana. Porque topava bem certinho. Porque era sagrado, né. Claro! Menstruação vem sagrado né! Então o corte da banana também era sagrado. Era de 28 a 30 dias que eles mandavam cortar banana. Era o corte da banana. E daí a gente tinha que ir... E eu me lembro, aaaaiiii! Eu ficava braba, braba. Que era muito sacrificoso o corte da banana. Então, de vez em quando eu ficava menstruada e a gente ficava lá o dia inteiro. Era muito ruim mesmo. A menstruação não é igual agora, não... Que tem essas facilidades. Era terrível!

Salete compara o seu corpo de mulher, o seu ciclo menstrual ao ciclo de corte da banana. Ela reproduz uma idéia de longa data, que vincula especialmente os corpos das mulheres à natureza: os ciclos da lua, as estações de colheita, a terra que é fértil ou a terra seca. As mulheres, conforme tal representação, seriam descontroladas, mais instintivas, instáveis e, por tal motivo, seriam uma ameaça à ordem das coisas, à ordem racional da sociedade, à civilidade.

Maria, 57 anos, conta da experiência de sua mãe, permeada de pavor da morte, da doença - sangue associado à doença, doença associada à desordem. Ela reproduz a moral católica aprendida por certo de sua mãe, que vivenciou a menarca como quem vive a proximidade da morte:

A minha mãe contava que quando ela ficou menstruada, a mãe dela já tinha morrido há muito tempo, e ela não sabia nada sobre isso. E quando ela menstruou, com 11 anos, ela ficou muito assustada, achando que ela ia morrer. Que era uma doença perigosa. E ela ia lá pra beira da sanga lavar. E rezava, rezava pra ela ficar curada. E com o tempo, curava. E ela achava

Anos 90, Porto Alegre, v. 14 n. 25, p.65-97, jul. 2007 
Entre vergonhas e silêncios, o corpo segredado...

que era a oração que tinha feito... Que Deus tinha curado ela. Aí no mês seguinte aparecia de novo. Aí ela rezava, rezava. Até que um dia a madrasta dela viu e chamou e explicou.

Ela rezou, remoendo-se de medo e vergonha. Maria tem 55 anos e fala de sua mãe, e é possível deduzir que se passaram aproximadamente setenta anos desse fato. E, na fala de Verônica, de 33 anos, esse tabu persiste:

Ficou mocinha. Aí a gente queria contar pras amigas, pras primas, mas aí... contar, não contar, nossa! Era um negócio assim que parecia que era o fim! Era o auge, né! Aí as amigas diziam "tu ficou?". E ficava naquela expectativa. Eu acho que elas tinham aquela certa dificuldade de dizer menstruação. As mães falavam: mo-ci-nha.

Sob a condição de segredar, elas tecem entre si redes de sociabilidade, apreendem e repassam códigos produzidos para falar sobre a menstruação, produzem discursos para organizar o segredo: "Ai, hoje estou com dor de cabeça', ou 'É muito', ou 'já faz três dias'. Só assim. Que quem é mulher entende" (Augusta, 78 anos).

Susan Sontag, em $A$ doença como metáfora, descreve fantasias punitivas ou sentimentais forjadas em torno da doença, os estereótipos do corpo doente, o uso da doença como um símbolo ou metáfora (Sontag, 2002). Nas memórias de nossas entrevistadas apareceram noções da menstruação como uma doença especial, um estado de debilidade semelhante ao estado doentio. Mesmo nos dicionários encontramos os termos 'doença ligeira', ou 'perda uterina excessiva de sangue', expressões que refletem a cultura e aproximam o período de sangramento à doença. $\mathrm{O}$ discurso da Igreja reproduz a idéia de que menstruação é uma punição para as mulheres, tal qual Sontag identifica nas representações do câncer atributos punitivos. Segredada e considerada doença, a menstruação é metaforizada, de modo muito similar às doenças descritas por Sontag:

Anos 90, Porto Alegre, v. 14, n. 25, p. 65-97, jul. 2007 
Marlene de Fáveri e Anamaria Marcon Venson

Qualquer doença encarada como um mistério e temida de modo muito agudo será tida como moralmente, senão literalmente contagiosa. [...] O contato com uma pessoa acometida por doença tida como misteriosa malignidade afigura-se inevitavelmente como uma transgressão ou, pior, como a violação de um tabu. Os próprios nomes dessas doenças são tidos como possuidores de um poder mágico.(Sontag, 2002:10)

A experiência particular de cada uma dessas mulheres, aliada às representações culturais do seu grupo (mães, vizinhas, irmãs, etc.), apropriadas e reproduzidas, constituíram variados modos de vivenciar o corpo. A idéia de cuidar de si durante o período de sangramento relacionando-o a um estado doentio, de debilidade, construiu folclore a respeito da menstruação. Valquíria, 57 anos, conta que: "Molhar o pé na água, lavar a cabeça, comer banana, banho geral no primeiro dia, pois o sangue 'subia pra cabeça', 'suspendia' e a pessoa ficava louca. Não andar descalça, pois inchava, ficava com a barriga grande e o sangue podia suspender. E ficava louca”. E Alice, 54 anos, disse assim: "eu não me cuidava, andava no molhado e elas diziam que eu tinha cólica por causa disso. A falecida Dona E., que era parteira, me disse pra esquentar uma lata de água e colocar dois punhados de cinza e enfiar os pés ali dentro". E Margarida, 59 anos, é categórica no modo de falar que "tem um peixe que menstrua como uma mulher. Se uma mulher grávida comer esse peixe quando ele estiver menstruando é igual a tomar veneno. Esse peixe é a arraia".

Não temos intenção de negar as verdades de certa sabedoria popular ou medicina caseira, mas, algumas vezes, elas mesmas reconheceram certas representações como folclóricas: "Mania de não lavar a cabeça porque o sangue ia pra cabeça. Aí a pessoa ficava louca! Era uma mania que eles tinham. Mas eu nunca soube de ninguém que tivesse acontecido" (Rosa, 65 anos).

Num primeiro olhar, essas práticas parecem absurdas. Valquíria, 57 anos, disse: "Deixava de lavar o cabelo, tomar sorvete.

Anos 90, Porto Alegre, v. 14 n. 25, p.65-97, jul. 2007 
Entre vergonhas e silêncios, o corpo segredado...

É gelado. Porque o sangue era quente". É preciso observar que elas obedecem a uma lógica fundamentada: a noção de quente/frio sustenta a idéia de que a mulher menstruada, em estado semi-doentio, deveria se cuidar de maneira especial. Essas crenças reproduzem a idéia da menstruação como doença, mas é preciso observar que elas se constroem dentro de uma lógica particular. Luisa, 60 anos, queixouse: "Pois é. Hoje a gente a gente passa por ignorante. Mas naquela época era assim”. E, Salete, 56 anos: "elas diziam isso [não molhar a cabeça, etc.] pra nós e a gente respeitava porque acontece alguma coisa com o corpo da gente, sim!'. Também ouvimos das entrevistadas que para atrasar a menstruação, quando queriam ir à praia ou a uma festa, ou quando o fluxo coincidiria com a data do casamento, elas ingeriam comidas ácidas, ou "frias", como elas disseram, como por exemplo, suco de limão. E para adiantar a menstruação, elas tomavam chá de canela ou vinho, ou mesmo os dois combinados, mistura que servia também como abortivo. Práticas como essas foram estudadas pela historiadora Joana Maria Pedro, mostrando que foram recorrentes pela história (Pedro, 2003). Ora, as mulheres sempre inventaram métodos para cuidar de seus próprios corpos!

As pessoas lidam com as experiências com subjetividade. A mesma experiência de vida - menstruar - não constitui os mesmos sujeitos: cada pessoa se constitui diferenciadamente. Elas se apropriam das representações proibitivas, mas nem sempre fazem delas práticas, construindo um tipo de subjetividade subversiva, burlando prescrições, como relembra Augusta, 78 anos:

[...] “ai, não presta cruzar no rio", a nona dizia isso. Mas eu nunca deixei de tomar banho ou de lavar a cabeça, nunca deixei de cruzar dentro do rio. Aquilo era normal pra mim. A gente ia pra roça. Mas eu nunca fiquei com medo. Eu não ia ficar três dias com o cabelo sujo. Trabalhava na roça, não ia ficar três dias suada. Depois a minha nona dizia que o sangue subia pra cabeça... e aí eu pensava: mas como é que pode ser verdade? Até que elas contavam que tinha uma mulher que tinha lavado

Anos 90, Porto Alegre, v. 14, n. 25, p. 65-97, jul. 2007 
Marlene de Fáveri e Anamaria Marcon Venson

a cabeça e que o sangue suspendeu e foi pra cabeça e a menina tinha ficado louca. Eu não conhecia aquela menina, mas elas contavam. Mas eu nunca deixei de lavar. Quando a mãe falava, ah, a gente já tinha lavado.

Nas relações experimentadas está a cotidianidade, lugar dos imprevistos e dos improvisos. Michel de Certeau mostra-nos que o cotidiano prevê estratégias e táticas de sobrevivência, lugar das burlas e transgressões (Certeau, 1994) - afinal, as mulheres das quais estamos tratando falam desse "fazer diferente", "conspirar", "segredar", mas falar, transgredir. Certeau, estudioso das práticas culturais contemporâneas, sustenta com argumentos fundamentados que cada um inventa para si mesmo uma "maneira própria" de usar os produtos impostos. Ele crê na criatividade das pessoas ordinárias, na astúcia eficaz das práticas cotidianas, nas maneiras de fazer resistentes ao desenvolvimento da produção sócio-cultural; trata de analisar uma sutil rede de "antidisciplina" que é inventada cotidianamente pelos consumidores. Esse autor nos auxilia na análise das operações dos usuários, das táticas cotidianas de desvio, das diferentes práticas de inventividade e apropriação, ou re-apropriação. Certeau alerta que não devemos tomar os outros por idiotas, sugerindo confiar na inteligência e inventividade das pessoas comuns, nas suas artes de fazer, nas suas estratégias de viver.

Seus estudos nos ajudam a pensar as estratégias das mulheres para driblar as regras familiares impostas, as proibições, as censuras do falar, as dificuldades do período de menstruação. Ouvimos Estela, 62 anos: "Às vezes não tomava banho geral no primeiro dia, no segundo dia. A cabeça ficava três dias sem lavar. Mas sabe né, esses cuidados assim, a gente era da colônia, quando a gente se sujava a gente se lavava mesmo...”. E, ainda, Cândida, 89 anos: "Não, não. Eu ia pra roça! Não, tinha ali aquelas bobocas. A mãe do V. não ia pra roça quando ficava menstruada. Ela não ia se molhar, ela não ia se... Ela se lavava pouco. Nós não. Era descalço. Não... Ô! Direto pra roça”. 
Entre vergonhas e silêncios, o corpo segredado...

Por certo, muitas mulheres utilizaram a menstruação para deixar de fazer trabalhos exaustivos, ou para amedrontar homens, ou para evitar relações sexuais com os maridos. De um lado, a representação da menstruação como doença, como debilidade, como periculosa serviu para impedir e calar essas mulheres. Mas de outro lado, elas se reapropriavam desses sentidos atribuídos à menstruação e ao corpo feminino para improvisar pretextos e esquivar-se de situações indesejadas. Observo que algumas mulheres tinham tanta vergonha de seu estado, que nem sequer mencionavam a menstruação, elas viveram um cotidiano de medo e segredo. No entanto, dado que as relações são negociadas, se a mulher dissesse que estava menstruada - ou desse a entender seu estado - com a intenção de deixar de fazer determinado trabalho, por exemplo, e confiasse nas normas de pudor e resguardo do corpo, quem atestaria seu estado?

A menstruação foi usada, muitas vezes, para justificar debilidades, mas a maioria das depoentes disse que durante o sangramento "trabalhava igual". Entendemos que as representações da menstruação como causa de fragilidade são reapropriadas cotidianamente, são praticadas quando são convenientes, são vividas de maneiras diferentes conforme a situação. Inês, 53 anos, disse: "A gente trabalhava, tinha que tomar banho. A gente roçava arroz o mês inteiro, ninguém perguntava se podia entrar na água ou não. Onde a gente estava, ao redor, era tudo roxo, vermelho [dentro da granja de arroz]. Mas ninguém morreu por isso".

Vemos nessa narrativa que havia mulheres agricultoras que não tinham como esconder a menstruação em certas situações. A água vermelha na granja denunciava o seu estado. Inês fala com desgosto dessa experiência, diz que não tinha escolha, que precisava ir trabalhar e, ser mulher, ou estar menstruada, não atenuava ou impedia o trabalho. Salete, 56 anos, diferentemente, joga com as possibilidades, brinca com a idéia de fazer performances e se abster do trabalho duro: 
Marlene de Fáveri e Anamaria Marcon Venson

Por exemplo, menstruada não ia carpir feijão, porque senão o feijão ia morrer. E lá no porco, se a guria dizia: "Eu estou menstruada”, então tu fica aqui. Não vai nem lá perto. E as outras que não estavam iam né! Porque diz que estragava a carne por causa da temperatura não sei do quê. Ah, pois é! Por quê que eu não lembrei disso na hora de cortar banana né?! Mas a gente lembra sempre tarde demais! Bem que eu podia dizer: "Pois é, e se desandar todas as bananas lá?".

Em outra ocasião, Salete diz: "É uma reviravolta no corpo

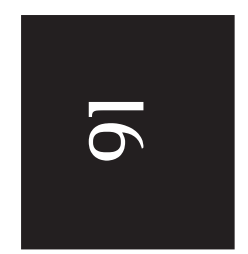
da gente, é normal. Mas nada que não se possa mais fazer as coisas". Essa noção não é fixa. Não está determinado o que se pode ou não fazer. As práticas referentes à menstruação são variáveis, as relações são negociadas. Proibições e prescrições se alternam quando convém na vida dessas mulheres.

A menstruação, ou o menstruar, produz crenças, condutas, comportamentos e rituais que se inserem em um sistema determinado de conceber o corpo das mulheres. Mesmo hoje, nas sociedades consideradas "modernas", as representações da menstruação obedecem a lógicas culturalmente específicas, marcam os corpos e têm efeitos na construção das subjetividades, pois essas marcas, além de efeitos simbólicos, têm expressão social e material. Elas permitem que essas mulheres sejam reconhecidas, incluídas ou excluídas, acolhidas ou recusadas, que usufruam de tais direitos, que realizem determinadas funções ou ocupem determinados postos, que tenham deveres e privilégios, que sejam aprovadas, toleradas ou rejeitadas.

Em suma, o corpo é construído através de processos continuados e permanentes, por investimentos e intervenções cotidianas. Entendemos que o sujeito não é um simples receptor de normatizações, mas ele participa ativamente. As mulheres das quais estamos falando respondem, resistem, reagem, mas também intervêm em seus próprios corpos para inscrever-lhes suas próprias marcas e códigos identitários para, às vezes, escapar ou confundir normas estabelecidas.

Anos 90, Porto Alegre, v. 14 n. 25, p.65-97, jul. 2007 
Entre vergonhas e silêncios, o corpo segredado...

Percebemos que as memórias de todas as nossas entrevistadas é marcada por lembranças de sofrimentos relacionados à menstruação. Em parte, essa idéia é herança da moral católica, que considera o sexo feminino um castigo. É também relevante o fato de que elas não tinham as possibilidades que temos hoje: elas contavam com os forrinhos e remédios caseiros. Salete, já na menopausa, disse: "Nunca usei absorvente, era só paninho". E, ainda, tanto medo e segredo, silenciamento forçado, nenhum tipo de educação sexual, causaram por certo muito sofrimento para essas mulheres. Depois de longa pausa, Joana, 63 anos, disse, num tom de voz consternador: "A minha tia nunca tinha me dito nada [ela foi criada com a tia]. Eu sempre me virei sozinha." E Cândida, 89 anos, com a mesma expressão de mágoa: "A minha irmã podia ter explicado prá mim, né”.

A memória, por si só, não seria história sem a conscienciosa escuta e o tratamento das fontes. Atentamos para o lugar de fala do historiador, ou seja, a historiadora e o historiador interpretam as ações do passado, dão um sentido outro para a memória; portanto, devem escavar as palavras, duvidar do que parece estar na superfície, interrogar o detalhe, perceber as diferentes versões produzidas no "calor da hora", desconfiar do testemunho, ter claro o lugar de intérprete. Desse modo, a memória, que remexe o passado e ressignifica sentimentos e sentidos, precisa da interpretação do historiador, não é história por si só. E, ainda, perceber que os relatos não são inocentes da memória, mas tentativas de convencer, formar a memória do outro.

Não é de nossa competência medir o quanto a experiência da menstruação foi desastrosa para essas mulheres, mas notar que a memória dessa experiência é relacionada à lembrança de sofrimentos, como fez Iara, 56 anos:

Eu passei um sufoco... E não contava pra mãe. Se vai em tal lugar, "ah, mas eu não vou". "Não vai por quê?". A gente não queria dizer que estava menstruada e tinha que ir. $\mathrm{Eu}$

Anos 90, Porto Alegre, v. 14, n. 25, p. 65-97, jul. 2007 
Marlene de Fáveri e Anamaria Marcon Venson

passei um sufoco. Sem orientação, sem nada, sem ir na médica, porque a mãe não levava. O sufoco era bastante, pra sair... Hoje eu não deixo de sair porque eu estou menstruada. [...] Com a minha filha eu vou ser totalmente diferente. Eu não quero ser igual, porque eu sofri com isso.

O que queremos dizer é que há diversas maneiras de vivenciar a menstruação: são diferentes mulheres, e cada uma vive sua cultura a sua maneira, muito particularmente, mesmo que tenham sido todas elas construídas, e educadas, para vivenciarem papéis ditos do feminino. Se os transgridem? Bem, segredar já é uma transgressão...

Among shames and silences, the confided body (Practices and representations women produce with the menstruation experience)

Abstract. This article is inserted in the analysis of cultural practices as well as their representations, as lived by women from different generations in the South of Santa Catarina State, perceived in the experience of the menarche emergence as a rite of passage. Our purpose is to understand how women, within the menarche experience, build representations of the feminine. Menstruation as a body manifestation, is only understood within a certain cultural context, so its meanings can only be understood within such contexts. For these analyses, the gender category encourages the idea that all kinds of silence, guided by senses of fear and shame, are understood as cultural constructions and bring about power relations. This situation is circumscribed in the imposition of the so called "feminine roles" by showing a body which is produced according to gender expectations. From the oral history perspective, the memory sources were precious for this work, being interpreted in the light of History methodologies.

Keywords: Menstruation. Gender relations. Representations. Body. Experience.

Anos 90, Porto Alegre, v. 14 n. 25, p.65-97, jul. 2007 




\section{Entre vergonhas e silêncios, o corpo segredado...}

CHARTIER, Roger. A História Cultural: entre práticas e representações. Lisboa: Difel, 1994.

ELIAS, Norbert. O Processo Civilizador: uma história dos costumes. 2. ed. Tradução Ruy Jungmann. v. 1/2. Rio de Janeiro: Jorge Zaahar, 1994.

FAUSTO-STERLING, Anne. Dualismos em duelo. Cadernos Pagu: desafios da eqüidade, v. 17/18. Campinas: UNICAMP, 2001/2.

FÁVERI, Marlene. Fontes educativas que a mulher camponesa de Navegantes/SC tem sobre a sexualidade - proposta educativa. 1989 Monografia (Especialização em Didática do Ensino Superior) - UNIVALI, Itajaí, 1989.

FINE, Agnès. Leite envenenado, sangue perturbado. Saber médico e sabedoria popular sobre os humores femininos (séculos XIX e XX). In: MATOS, Maria Izilda S. de; SOIHET, Raquel (orgs.). Corpo feminino em debate. São Paulo: Editora UNESP, 2003.

FOUCAULT, Michel. História da sexualidade 1: a vontade de saber. 10. ed. Tradução Maria T. e J. A. Albuquerque. Rio de Janeiro: Graal, 1988.

LAQUEUR, Thomas. Inventando o sexo. Corpo e gênero dos gregos a Freud. Rio de Janeiro: Relume Dumará, 2001.

LOURO, Guacira Lopes. Corpos que escapam. Estudos feministas. Brasília, n. 4. ago.dez. de 2003. Disponível em: < http:/ /www.unb.br/ih/his/gefem>. Acesso em nov. 2005.

NICHOLSON, Linda. Interpretando o gênero. Estudos Feministas. Florianópolis, CFH/CCE/UFSC, v. 8, n. 2/2000.

PEDRO, Joana Maria. Aborto e infanticídio: práticas muito antigas. In:

(org.). Práticas proibidas: práticas costumeiras de aborto e infanticídio no século XX. Florianópolis: Cidade Futura, 2003.

PERROT, Michelle. Os silêncios do corpo da mulher. In: MATOS, Maria Izilda Santos de SOIHET, Rachel (orgs.). Corpo feminino em debate. São Paulo: Editora UNESP, 2003.

PRINS, Baukje; MEIJER, Irene Costera. Como os corpos se tornam matéria: entrevista com Judith Butler. Estudos Feministas. Florianópolis, CFH/CCE/UFSC, v. 10, n. 1, 2002.

RANKE-HEINEMANN, Uta. Eunucos pelo reino de Deus: mulheres, sexualidade e a Igreja Católica. Tradução Paulo Fróes. Rio de Janeiro: Record: Rosa dos Tempos, 1996.

Anos 90, Porto Alegre, v. 14, n. 25, p. 65-97, jul. 2007 
Marlene de Fáveri e Anamaria Marcon Venson

SCOTT, Joan W. Experiência. In: SILVA, Alcione Leite da; LAGO, Mara Coelho de Souza; RAMOS, Tânia Regina Oliveira (orgs.). Falas de gênero: teorias, análises e leituras. Florianópolis: Mulheres, 1999.

SCOT'T, Joan. Gênero: uma categoria útil de análise histórica. Educação e realidade. Porto Alegre, 16 (2): 5-22, jul.-dez. 1990.

SONTAG, Susan. A doença como metáfora. Tradução: Mário Ramalho. São Paulo: Graal, 2002.

VIGARELLO, Georges. O limpo e o sujo. Tradução Mônica Stahel. São Paulo: Martins Fontes, 1996.

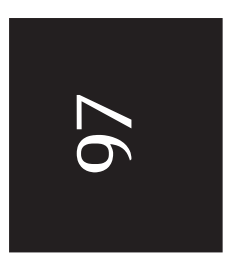

Recebido em 02/08/2007 autoras convidadas 